\title{
Priority in Managing Health Intervention Program: A Critical View
}

\section{Context:}

Priority is a preferential rating that indicates importance or urgency, according to given criteria. (1) Scarce resource with relative components is the rational basis to think, design and set choice within its limitation upon selecting any priority, while managing health intervention program. Priority is thus the rational and scientific choice made by the manager for an action. The health manager starts the essence of its beginning and ends with predetermined frame-work with the managerial methodology i.e. the process. There are various ways to analyze priority but basic priority rating process framed by Spiegel \& Hyman in 1978 was one of typical and most useful process; which is described below. (2) The process of priority is the product of four components along with its sub-components divided by three; which is illustrated by following equation:

$\mathrm{P}=\frac{(\mathrm{A}+\mathrm{B}) \mathrm{C}}{3} * \mathrm{D}$

- Component A : Size of Problem

- Component B : Seriousness of Problem

- Component $\mathrm{C}$ : Effectiveness of the Intervention

\author{
Nayak SK ${ }^{1}$ \\ ${ }^{1}$ District Health Office, Gulmi, Nepal
}

- Component D : Propriety, Economics, Acceptability, Resources and Legality (PEARL)

While setting priority; situation analysis, need assessment and evidence based intervention are also some crucial factors to be taken in the priority process at different levels viz. policy level, implementation level and intervention level. All those components depict an idea to reasoning, rationing and prioritizing one of the most needs, problems and area of interests. Selection of one or more among limitations and scarcities makes a manager to adopt the best one and it results with unavoidable consequence of limitation and scarcity. It is also known as rationing/prioritizing. In 2002, Shiell et al mention that if resources are not sufficient to meet all "needs" then some needs must be left unmet and priority should be given to services that best meet one's objectives. So, priority setting refers to the process of deciding which needs should be met and which needs cannot be met, at least not immediately. (2)

Sequential order of prioritized health problems, program, activities or health event can also be organized in a tabular form using prioritization format as given below. (3)

Table 1. Prioritization format for ranking health problems, program, activities or health event:

\begin{tabular}{c|c|c|c|c|c|c}
\hline \multirow{2}{*}{ SN } & $\begin{array}{c}\text { Health } \\
\text { problem or } \\
\text { condition }\end{array}$ & Mortality & Morbidity & $\begin{array}{c}\text { Resource and feasibility in } \\
\text { terms of resources (how } \\
\text { preventable, cost benefit or } \\
\text { cost effective) }\end{array}$ & $\begin{array}{c}\text { Public health } \\
\text { significance and not } \\
\text { being addressed by } \\
\text { other agency }\end{array}$ & $\begin{array}{c}\text { Social significance } \\
\text { (economic development, } \\
\text { productivity). }\end{array}$ \\
\hline 1. & & & & & & \\
\hline 2. & & & & & \\
\hline
\end{tabular}

\section{National Scenario}

Second Long Term Health Plan (SLTHP) 1997-2017 mentions that the burden of disease study provided a basis for prioritizing health intervention programs to meet the health needs of the majority of the population and significant problems were noted, constraints identified, policy issues/policy options were generated and prioritized. SLTHP has indicated that priority be given to health promotion and prevention activities based on primary health care principles. It has also identified Essential Health Care Services (EHCS) that addresses the most essential health needs of the population and that are highly cost effective. EHCS are priority public health measures and are essential clinical and curative health services for appropriate treatment of common disease and illness. $(4,5)$ Nearly seventy percent $(70 \%)$ of disease burden and more than eighty percent $(80 \%)$ of deaths are directly and indirectly related with the four prioritized essential health care services viz. 1. Family planning, Safe motherhood and Neonatal health; 2. Child health; 3. Communicable disease control, 4. Out-patient care. If prioritized essential health care services are implemented in a proper way, disease burden and mortality can be reduced dramatically. (5) In Health Care Delivery System of Nepal, there are three category of programs P1, P2 and P3 based on descending order of priority annually conducted throughout the country. Programs in the first priority (P1) comprise Expanded vaccination (now called National Immunization Program) and National Polio 
vaccine; Control of Acute Respiratory Infection; Control of Diarrheal Disease; Nutrition; Safe motherhood/Maternal and Child Health; Family planning; Reproductive Health of the adolescent; Female Community Health Volunteers and Sudenis (Trained Traditional Birth Attendants, now phased-out); Epidemiology and control of diseases (Control of Malaria; Kalaazar Elimination; Natural disaster and management; Vectorborne diseases and their control; research and training; Tuberculosis Control Program; Leprosy Control Program; Control of HIV/AIDS and Sexually Transmitted Diseases); Health Education, Communication and Education; Supply management; Community medicine; Community Drug and Health Insurance Program; Integrated Supervision, Medicine, Equipment and Hospital Construction, Renovation and Maintenance. Program in second priority (P2) comprise National Health Training; Bir Hospital; Sahid Shukraraj Tropical and Infectious Disease Hospital; Kanti Children's Hospital; HRH Indra Rajya Laxmi Maternity Hospital; Urban Health; Ayurveda Services; Laboratory and other auxiliary service; Strengthening supervision, monitoring and evaluation systems; Blood bank and blood transfusion services; Health research. Program in third priority (P3) comprise Nepal Eye Hospital; Netra Jyoti Sangh, BP Koirala Memorial Cancer Hospital; BP Koirala Health Science Foundation Dharan; Sahid Gangalal National Heart Centre, Dental care service; Ayurveda Hospital, Naradevi; Singha Darbaar Vaidyakhana; Homoeopathy; Unani; Naturo-therapeutics, Management of medicines, Post-graduation; Hospital development and extension; Control of addictive drugs. (6,7) Among different programs, there are diversity in priority setting because of its typology. Hence, in health sector; we must have to choose the one and the another in sequence or a package of interventions logically; so that the objectives are met with a view to cyclical impact. The health service programs were prioritized in the Tenth plan on the following basis: Burden of diseases; Implementing capacity; Equity; Program targeted to the poor, the oppressed and those deprived of opportunities; Program contributing to poverty eradication; availability of resources.7 EHCS has addressed twenty essential health care services; namely 1. Appropriate treatment of common disease and injuries 2. Reproductive Health 3.Expanded program on immunization and Hepatitis B vaccine 4. Condom Promotion and Distribution 5. Leprosy Control 6.Tuberculosis Control 7. Integrated Management of Childhood Illness 8.Nutritional Supplementation, enrichment, nutrition education and rehabilitation 9. Prevention and Control of blindness 10. Environmental Sanitation 11. School health Services 12. Vector borne disease control 13. Oral Health Services 14. Prevention of deafness 15.Substance abuse including tobacco and alcohol control 16. Mental health services 17. Accident prevention and rehabilitation 18 . Community based rehabilitation 19. Occupational Health 20. Emergency preparedness and management. (8)

\section{Critical view}

Key drawbacks of those mentioned prioritized health intervention programs, activities, health event or any problems are hidden in either structure-to-strategy or strategy-to-struc- ture adoption process in Nepal. In fact, we have week monitoring of almost all prioritized interventions except few ones. In practice, we make ad hoc basis priority formulation and adoption of new policy implementation without pilot study. Actually, there are lack of sufficient evidence based priority regarding health problems in Nepal. In practice, there is existence of top to bottom planning process and bottom to top planning process has been poorly intervened; which has created priority process in shadow. Hence, priority process should be practiced proportionately as either direction i.e. from top to bottom and vice versa with a determined framework, strengthened surveillance system and annual event of national health assembly. Also, situation analysis, need assessment and health impact assessment should be carried out periodically in order to know priority setting in contribution to health sector development. Study of policy/system for priority can also be incorporated, so that priority would be recommended for new direction with convergence of works.

Current scenario of communicable diseases, non-communicable diseases, climate change, developmental issues, population management, public/health study, quality health work force and health cadre development including proper infrastructure development and formulation of new health policy should be kept in mind. P1,P2,P3 are in old version and should be revised, up-dated and re-newed incorporating in new health policy. Similarly 20-EHCS should be revisited and reformulated with some revisions taking point consideration in primary health care approach in most to least priority order.

Overall management of health program intervention in any catchment area of the country should be followed by determined Plan of Action as per event of National Health Assembly/Provincial Health Assembly/Local Health Assembly. In this context, Public Health Right is the continuum priority to govern the public health activities, programs by sound management/administration. Also, Healthy Public Policy stands the central issue and it must be addressed in Public Health Act; so that expected prioritized public/health problems/issues/events/program /activities and works can be institutionalized in standard priority process at each and every level of National Health System.

I would like to express my concluding remarks that "National Health System should have the structure like: Ministry of Public Health, with Department of Hospitals under that structure including other ones ". It will develop the strengthened priority process. The new health policy should have consideration upon its advocacy.

\section{References :}

1. McMahon R., Barton E., Piot M., Gelina N. and Ross F. On Being in charge: A guide to management in primary health care. 2nd Edn. WHO publication. World Health Organization (WHO) Geneva;1992. p. 471.

2. Kishore J. A Dictionary of Public Health. 2nd Edition. Century Publications 46, Masih Garh, P.O: Jamia Nagar, New Delhi 110025, India; 2007 AD. p. 707-708

3. Pradhan H.B. A Text Book of Health Education (Philosophy and Principles). 4th Edition: 2003. Educational Publishing House 
PO Box 5178 Jamal, Kathmandu; 2003, p. 54.

4. Government of Nepal (GoN). Ministry of Health and Population (MoHP). Second Long Term Health Plan (SLTHP) 19972017: Perspective Plan for Health Sector Development. Published by Health Sector Reform Unit Kathmandu, Nepal; 2007 AD. p. 3.

5. Government of Nepal (GoN). Ministry of Health and Population (MoHP). Deparment of Health Services (DoHS). Management Division (MD). District Health Services Management Reference Manual: Module Two; 2065 BS ( 2008 AD). p. 109.

6. Government of Nepal (GoN). Ministry of Health and Population (MoHP). Deparment of Health Services (DoHS). Sthaniya Swasthya Sewa Byabasthapan Abhimukhikaran Pustika (Local Health Services Management Orientation Manual); 2065 B.S. (2008 AD). p.12

7. Government of Nepal (GoN). Ministry of Health and Population (MoHP). Deparment of Health Services (DoHS). Annual Report; 2063/2064 BS (2006/2007 AD). p. 20-21.

8. Government of Nepal (GoN). Ministry of Health and Population (MoHP). Elements of Essential Health Care Services: Main Interventions or Program Components. Kathmandu, Nepal; April, 2000 AD. p. 80. 